\title{
Design, Control and Analysis of Low Cost Archetype Dual Rotor Helicopter for Educational Institution
}

\author{
A. P. S. Ramalakshmi' , P. S. Manoharan ${ }^{2 *}$ \\ ${ }^{1}$ Department of Electrical and Electronics Engineering, K. L. N. College of Engineering, Sivagangai, India \\ ${ }^{2}$ Department of Electrical and Electronics Engineering, Thiagarajar College of Engineering, Madurai, India \\ Email: "psmeee@tce.edu
}

Received 11 May 2016; accepted 20 May 2016; published 29 August 2016

Copyright (C) 2016 by authors and Scientific Research Publishing Inc.

This work is licensed under the Creative Commons Attribution International License (CC BY).

http://creativecommons.org/licenses/by/4.0/

(c) (i) Open Access

\begin{abstract}
This paper presents the design and development of low cost archetype dual rotor helicopter (LCADRH) for academic research in an educational institution. The LCADRH is installed with optical pitch encoder and yaw encoder which measure elevation and side to side motion of helicopter. The objective of the project is to design and integrate the helicopter with data acquisition board and sensors to provide hardware features, software support capability for its rapid real time measurement and control. The low cost designed LCADRH facilitates the academic research for students in the institution and is able to provide hands on training to understand the concept of nonlinearity, system modelled and unmodelled dynamics and uncertainty, modelling, simulation and control by doing practical experiments. The mathematical model of the LCADRH is derived using grey box modelling method. The control of LCADRH is challenging due to its nonlinearity and effect of strong coupling between aerodynamic forces and torques generated by the both pitch and yaw actuators. In closed loop position control of LCADRH, pitch and yaw axis motion is regulated using linear quadratic controller (LQR). Encouraging results are obtained both in simulation and hardware.
\end{abstract}

\section{Keywords}

Low Cost Archetype Dual Rotor Helicopter (LCADRH), System Identification, Linear Quadratic Regulator (LQR), Grey Box Model (GBM), Prediction Error Method (PEM)

\section{Introduction}

Earlier some research was done on helicopter and its control in foreign countries [1]-[4]. The cost of helicopter ${ }^{*}$ Corresponding author.

How to cite this paper: Ramalakshmi, A.P.S. and Manoharan, P.S. (2016) Design, Control and Analysis of Low Cost Archetype Dual Rotor Helicopter for Educational Institution. Circuits and Systems, 7, 3329-3342. 
model is very high where developing countries could not afford. To encourage the research on control system in academic institution in developing countries, LCADRH is designed and developed for the students. The helicopter is controlled in two degrees of freedom (2-DOF). In future, control oriented design related to 3-DOF can be extended [5]-[7]. The system identification of nonlinear system like helicopter plays a major role for its precise control subject to system dynamics and uncertainty [8]-[10]. Research work is carried out on grey box system identification for model helicopter in [11]. The small scale unmanned rotorcraft system is modeled using system identification for the flight control in [12]. Prediction error method of LPV models is done in [13]. LQR control was successful for aerospace engineers for the flight control provides good stability and control [14] [15]. LQR controller design for helicopter control was done in 2-DOF [16] [17]. Helicopter control is highly tedious due to the presence of nonlinear dynamics and uncertainty. Research work on helicopter control is necessary due to the demand of precise control in emergency conditions like earth quake, fire accidents. Nonlinear control of 2-DOF helicopter research is carried out in [18]-[20].

In this paper, the mathematical model of LCADRH is identified using system identification. The main components of LCADRH is designed and integrated to get a helicopter prototype. The effect of nonlinearity and inherent coupling existence are observed in closed loop position control. Therefore, proposed LCADRH model can be used for providing hands-on training for undergraduate and postgraduate students in the area of modelling and control of nonlinear system. The block diagram of proposed system is shown in Figure 1. The LQR controller is designed for the closed loop position control of LCADRH.

\section{Design of Mathematical Model}

\section{System Identification}

There are many methods available for system identification of non-linear MIMO systems using measured input-output data such as black box modelling, grey box modelling etc. In this paper, we design an indigenous archetype dual rotor helicopter and its dynamics are modelled by grey box modelling. Using the system identification tool in MATLAB an idnlgrey object of this model is created and the unknown idnlgrey model parameters and initial states using measured data are estimated by prediction error method (PEM). The PEM is a parametric estimation method in which the system parameters are found out providing the initial set of values. Here the initial values are set by physical interpretation and presumption.

The objective of the PEM is to minimize the prediction error by the prediction parameter which minimizes the variation of prediction error,

$$
e(t, p)=y(t)-\bar{y}(t, p)
$$

where,

$e(t, p)$ is the prediction error,

$y(t)$ is the model output,

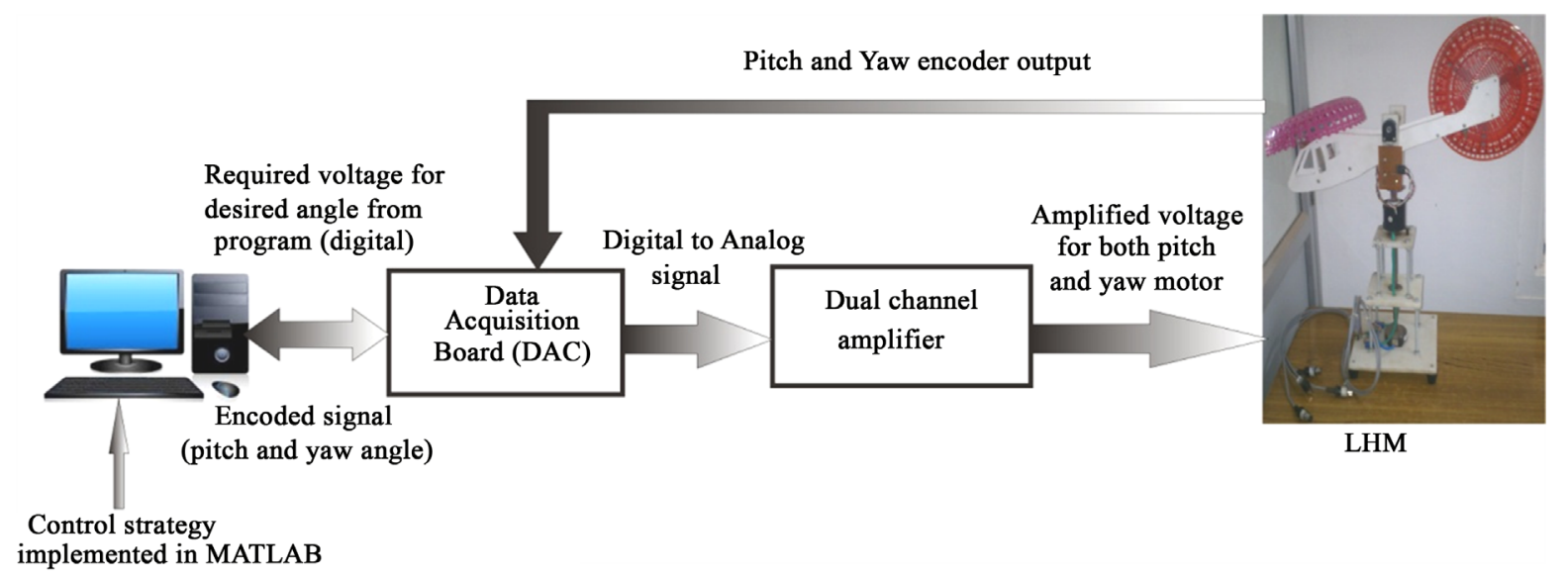

Figure 1. Block diagram of Low cost archetype dual rotor helicopter system for academic research. 
$\bar{y}(t, p)$ is the predicted estimate of the output,

$p$ is the vector containing all unknown parameters,

$\bar{p}$ is the vector containing predicted parameters,

$t=0,1,2, \cdots, n-1$,

$n$ is the number of data samples.

The PEM uses optimization to minimize the cost function. Initially the state space matrixes A, B contains the coefficients with initial value of fixed parameters and some fixed values. The estimating algorithm estimates the parameters in A and B matrix. The model is estimated using PEM with so far determined parameters as the initial values in MATLAB. To validate this method, a simulation model is used to generate the data for the system identification.

\section{LQR Controller Design}

While designing controllers for complex systems with stringent performance requirements, LQR method is used. It is a powerful method to find the best controller that minimizes cost. It is mainly used where the system dynamics are given by a set of linear equations and the cost is given by a quadratic function. Here the weighting factors are supplied by a human. The settings of the controller are found by using a mathematical algorithm that minimizes the cost function. Q and $\mathrm{R}$ are the two matrices that parameterize the cost function. They weight the state vector and the system input respectively. LQR method tries to achieve optimal control by solving the algebraic riccatti equation.

The LQR controller is designed for linear state space model of LCADRH,

$$
\dot{x}=A x+B u
$$

The states of LCADRH are,

$$
x=\left[\begin{array}{llll}
\theta & \psi & \dot{\theta} & \dot{\psi}
\end{array}\right]^{\mathrm{T}}
$$

where

$\theta$ is pitch angle,

$\psi$ is yaw angle,

$\dot{\theta}$ is angular pitch velocity,

$\dot{\psi}$ is angular yaw velocity,

and the input $u$ of LCADRH are,

$$
u=\left[\begin{array}{ll}
V_{m, p} & V_{m, y}
\end{array}\right]^{\mathrm{T}}
$$

where

$V_{m, p}$ is pitch motor voltage

$V_{m, y}$ is yaw motor voltage

$$
u=-K_{R} X
$$

satisfies the following cost function,

$$
J(u)=\int_{0}^{\infty}\left(x^{\mathrm{T}} Q x+u^{\mathrm{T}} R u\right) \mathrm{d} t
$$

where $Q$ and $R$ are the weighting matrices that to be designed such that subject to the system dynamics.

\section{Low Cost Design of Dual Rotor Helicopter Prototype in 2-DOF}

The main components of LCADRH are 12V DC servo motor, 6V DC servo motor, optical pitch encoder, optical yaw encoder, hollow shaft slip ring and motor power circuit. The LCADRH shown in Figure 2 is designed and integrated for the control of elevation about the pitch axis and side to side motions about yaw axis. 12V DC servo motor drives the pitch propeller for elevation and 6V DC servo motor drives the yaw propeller for side to 


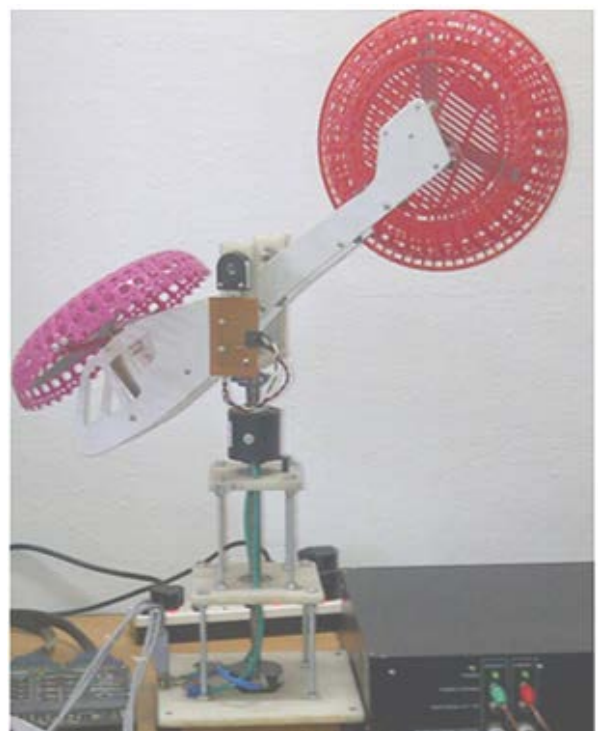

Figure 2. Low cost designed two rotor helicopter model for academic research.

side motions. Optical pitch encoder and optical yaw encoder provides the digital position feedback information. The hollow shaft slip ring is used to transfer power of two motors and optical pitch encoder signal without tangling of wires.

\section{System Specification and Cost Details}

The main components of LCADRH are shown in Figure 3. Table 1 summarizes the specification of components and angle range of pitch and yaw of LCADRH. The Table 2 shows the overall cost detail of LCADRH. The total cost for the complete design of LCADRH is $\$ 894.51$. The designed helicopter model in low cost is beneficial for the students in academic institution to test and explore modern identification and control methodologies.

\section{Results Discussion}

\subsection{Closed-Loop Position Control of LCADRH}

The position control of LCADRH in open loop is tedious due to high nonlinearity and strong coupling effect. In open loop, LCADRH tend to change yaw position when pitch nose goes up and down and vice versa due to the existence of coupling effect between pitch and yaw actuators. The LQR closed loop position control of LCADRH is done under four cases to analyze the coupling effect that exists between the pitch and yaw actuators. In case I, the pitch angle is varied by giving step input of 10 degree whereas yaw angle is constant at 0 degree. In case II, yaw angle is varied by giving step input of 30 degree while the pitch angle is constant at 0 degree. In case III, the elevation of LCADRH is raised by setting pitch angle to square input with the amplitude of 5 degree and frequency of $0.05 \mathrm{~Hz}$ whereas the yaw angle is constant at 0 degree. In case IV, side to side motion is increased by setting the yaw angle to square input of 30 degree and frequency of $0.05 \mathrm{~Hz}$ and the pitch angle is constant at 0 degree. The objective of this closed-loop position control is to compare the measured closed-loop response with simulated response. The LQR controller gives encouraging results in reducing coupling effect, structural vibration and oscillation.

\subsection{Case I-Pitch Step Input}

To analyze the coupling impact of LCADRH MIMO system in LQR closed loop position control, the first control variable $\theta$ is varied by keeping second control variable $\psi$ as constant at 0 degree. The simulated pitch and yaw position response tracks the reference with less steady state error. The measured pitch angle is 10.2 degree at $t=1.478 \mathrm{~s}$. The steady state error of measured pitch angle is very less at time $t=20 \mathrm{~s}$ to $\mathrm{t}=30 \mathrm{~s}$ as 


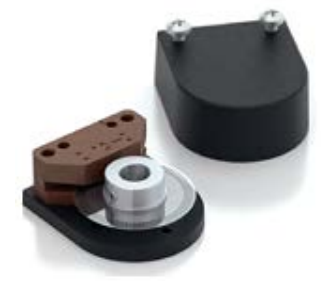

(a)

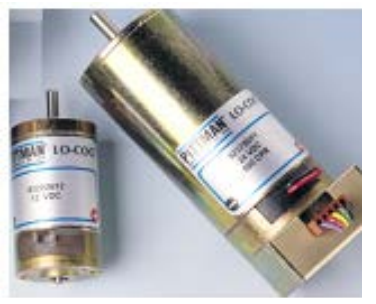

(c)

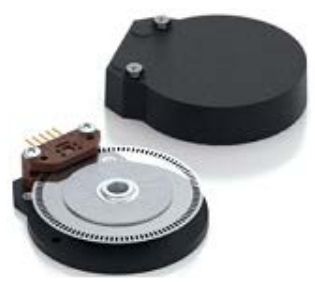

(b)

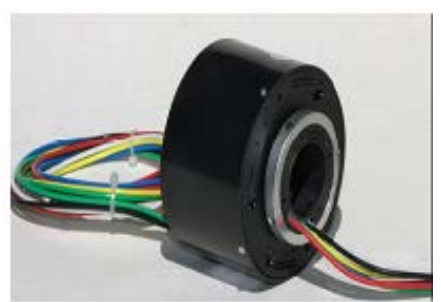

(d)

Figure 3. Main components of LCADRH (a) Pitch encoder; (b) Yaw encoder; (c) Pitch and Yaw motor; (d) Slip ring.

Table 1. LCADRH specification.

\begin{tabular}{cc}
\hline Component/Parameter & Specification \\
\hline Pitch motor & $\pm 12 \mathrm{~V}$ \\
Yaw motor & $\pm 6 \mathrm{~V}$ \\
Pitch angle & 0 to 45 degree \\
Yaw angle & 0 to 360 degree \\
Optical pitch encoder & 128 to 5000 pulses per revolution \\
Optical yaw encoder & 256 to 10,000 pulses per revolution \\
Hollow shaft slip ring & 2 A \\
Pitch propeller thurst force constant & $1.037 \mathrm{~N} / \mathrm{V}$ \\
Yaw propeller thurst force constant & $0.428 \mathrm{~N} / \mathrm{V}$ \\
\hline
\end{tabular}

Table 2. Cost detail of LCADRH.

\begin{tabular}{cc}
\hline Main component of LCADRH & Cost (in USD) \\
\hline Pitch 12V DC servo motor & 107.19 \\
Yaw 6V DC servo motor & 252.00 \\
Optical pitch encoder & 62.32 \\
Optical yaw encoder & 73.00 \\
Hollow shaft slip ring & 316.00 \\
Other Accessories (Pitch propeller, yaw propeller, Helicopter body, motor circuit, & 84.00 \\
spindle, propeller shield, cables, connecting wires, bearing, yoke, screws, nuts etc.) & 894.51 (in USD) \\
\hline
\end{tabular}

shown in Figure 4(a). Moreover deviation of measured pitch angle is also very less as shown in Figure 4(a). The difference between the simulated and measured pitch angle is 0.5 degree. The experimental result of pitch angle tracks the desired pitch angle consistently. By conducting this experiment, it is observed that there is less coupling impact of elevation motion of LCADRH on yaw axis as shown in Figure 4(a). Figure 4(a) depicts 

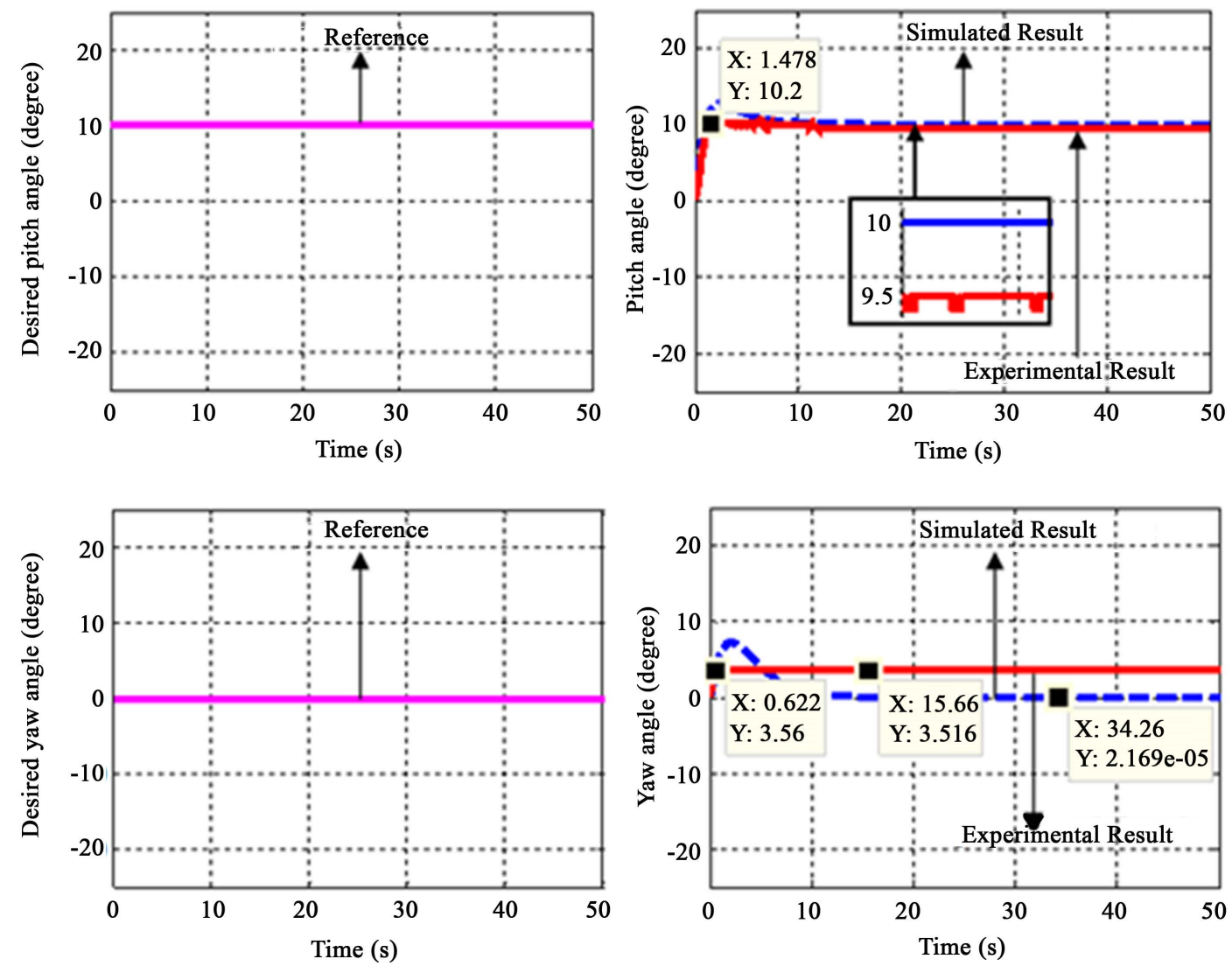

(a)

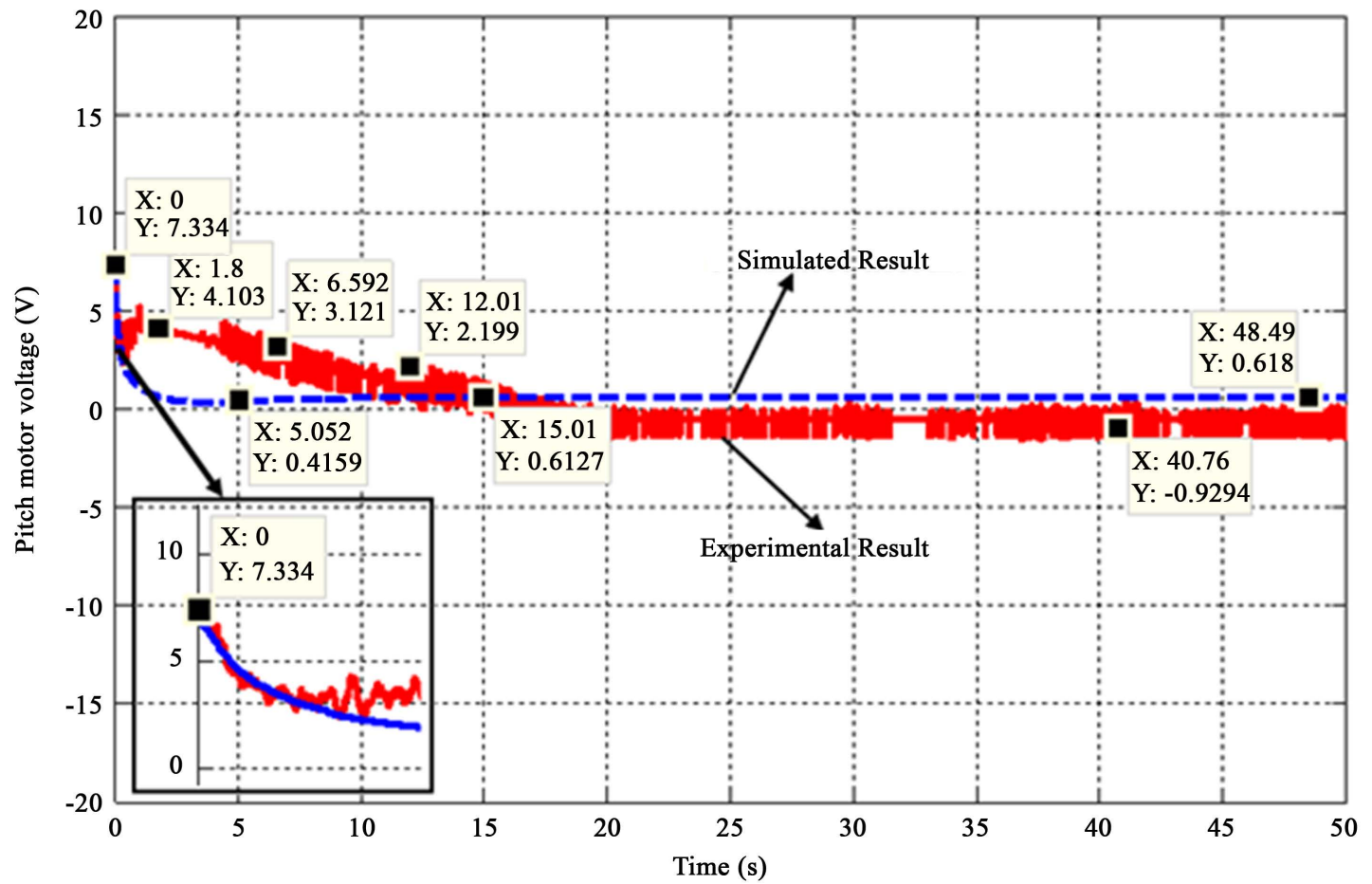

(b) 


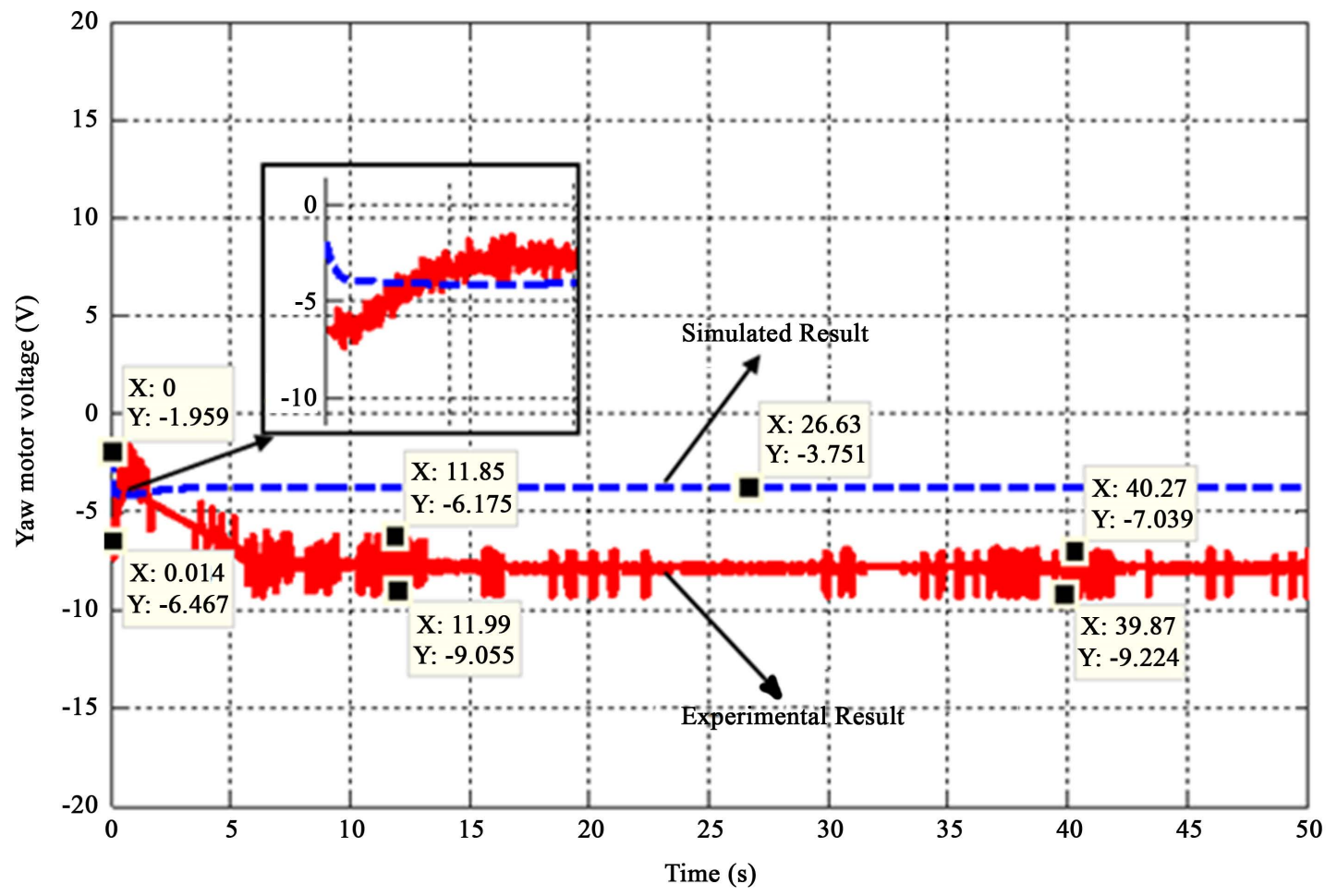

(c)

Figure 4. LCADRH MIMO system outputs (a) LQR controlled closed loop position response under pitch step input (b) and (c) Motor input voltages.

LCADRH rotates about the yaw axis by 3.56 degree at $\mathrm{t}=0.622 \mathrm{~s}$ due to the rise of elevation about pitch axis by 10 degree. This is due to the generation of rotary force by pitch motor about the yaw axis. From $t=10 \mathrm{~s}$ to $t=50$ $\mathrm{s}$, the measured yaw angle is constant at 3.516 degree. It is observed from the results that the implementation of LQR controller for the closed loop position control of LCADRH gives better result in tracking the desired pitch angle. From the experimental result of pitch and yaw angle, it is observed that structural vibration is purged. Therefore LCADRH is designed well at low cost.

The Figure 4(b) and Figure 4(c) shows the input voltage of pitch and yaw motor. Initially when the elevation of LCADRH is raised about an pitch axis at time $\mathrm{t}=0 \mathrm{~s}$, the pitch motor voltage is $7.334 \mathrm{~V}$. LCADRH goes down about an pitch axis by the decrease of yaw motor input voltage from $-1.959 \mathrm{~V}$ at $\mathrm{t}=0 \mathrm{~s}$ to $-9.056 \mathrm{~V}$ at $\mathrm{t}=$ 11.99 s. The measured pitch and yaw motor input voltage in Figure 4(b) and Figure 4(c) shows less variation.

\subsection{Case II-Yaw Step Input}

In this case, coupling existence between the pitch and yaw actuators of LCADRH is observed by giving step input of 30 degree about yaw axis. The simulated pitch and yaw angle possess consistent tracking of desired pitch and yaw angle as shown in Figure 5(a). The pitch motor simulated voltage of $10 \mathrm{~V}$ causes the overshoot on yaw axis by angle 5.28 degree from reference. Then eventually simulated yaw angle tracks the reference with the error of 0.07 degree from $t=30 \mathrm{~s}$ to $t=50 \mathrm{~s}$. As shown in Figure 5(a), initially the measured pitch angle has overshoot of 9.58 degree when the yaw motor input voltage is $7.034 \mathrm{~V}$. This yaw motor voltage is the reason for the generation of torque on pitch axis. Experimental result depicts then the pitch angle eventually stabilizes at $\mathrm{t}=6.186 \mathrm{~s}$. The measured pitch angle is 0 degree at $\mathrm{t}=10 \mathrm{~s}$ to $\mathrm{t}=50 \mathrm{~s}$. Experimental result shows that the absence of coupling impact of yaw actuator on pitch axis. The $10 \mathrm{~V}$ applied to the pitch motor at $t=0.1 \mathrm{~s}$ generates a torque on yaw axis. The measured yaw angle tracks the desired yaw angle with the error of 2.43 degree which is very less.

The Figure 5(b) and Figure 5(c) shows the pitch an yaw motor input voltages. As illustrated in Figure 5(b), motion about the pitch axis tracks the reference exactly when pitch motor voltage is approximately $-1.635 \mathrm{~V}$. 

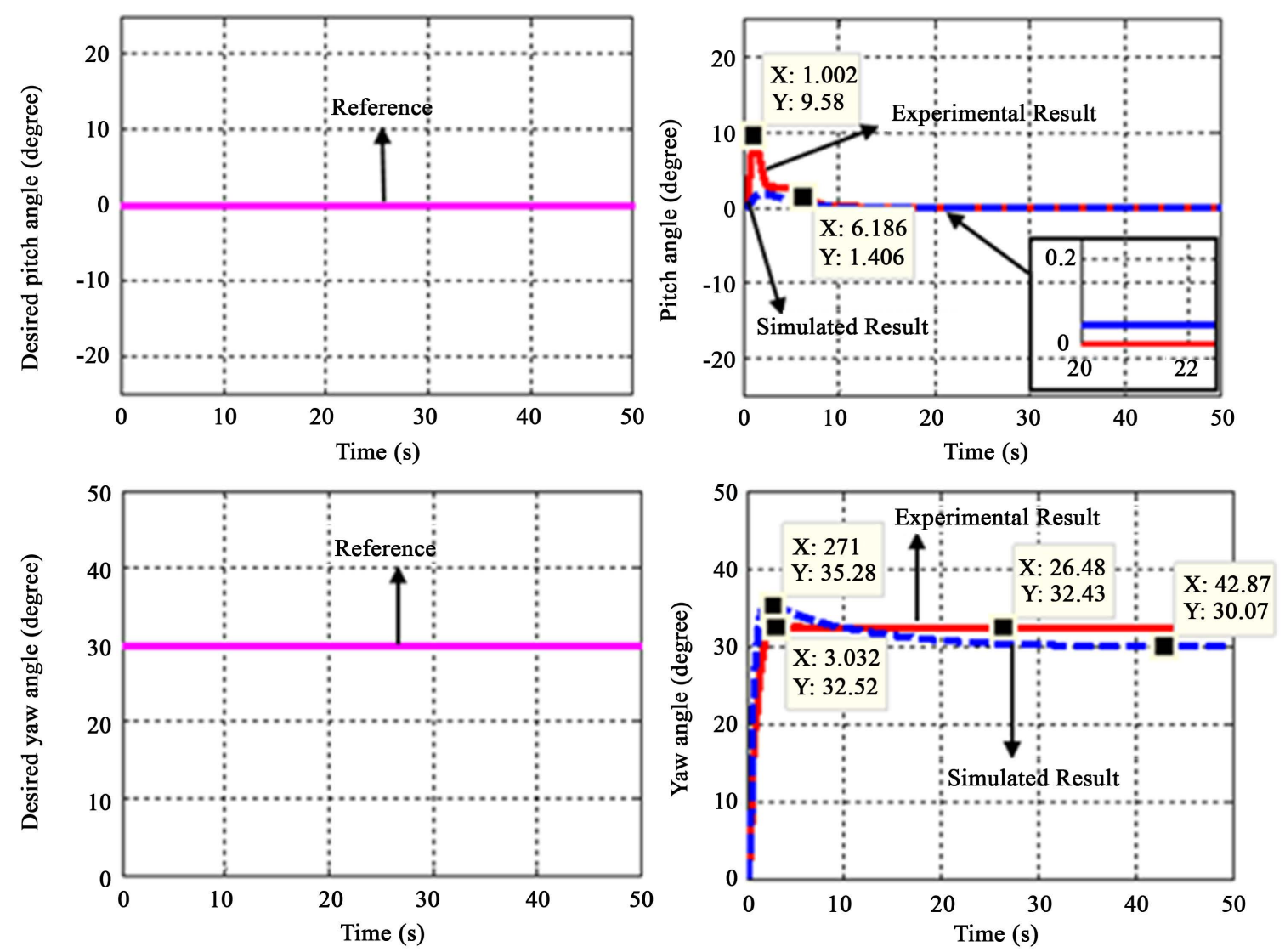

(a)

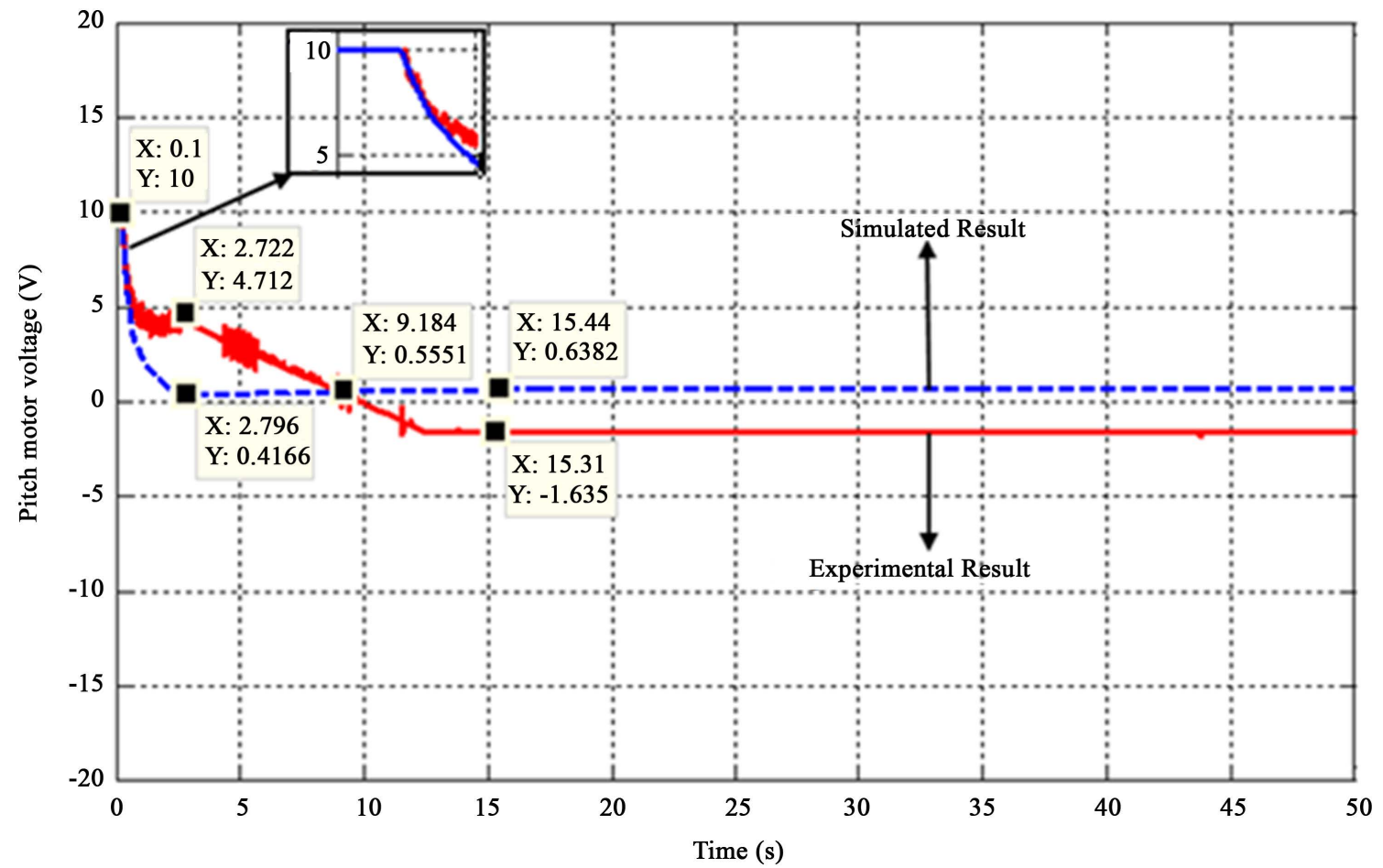

(b) 


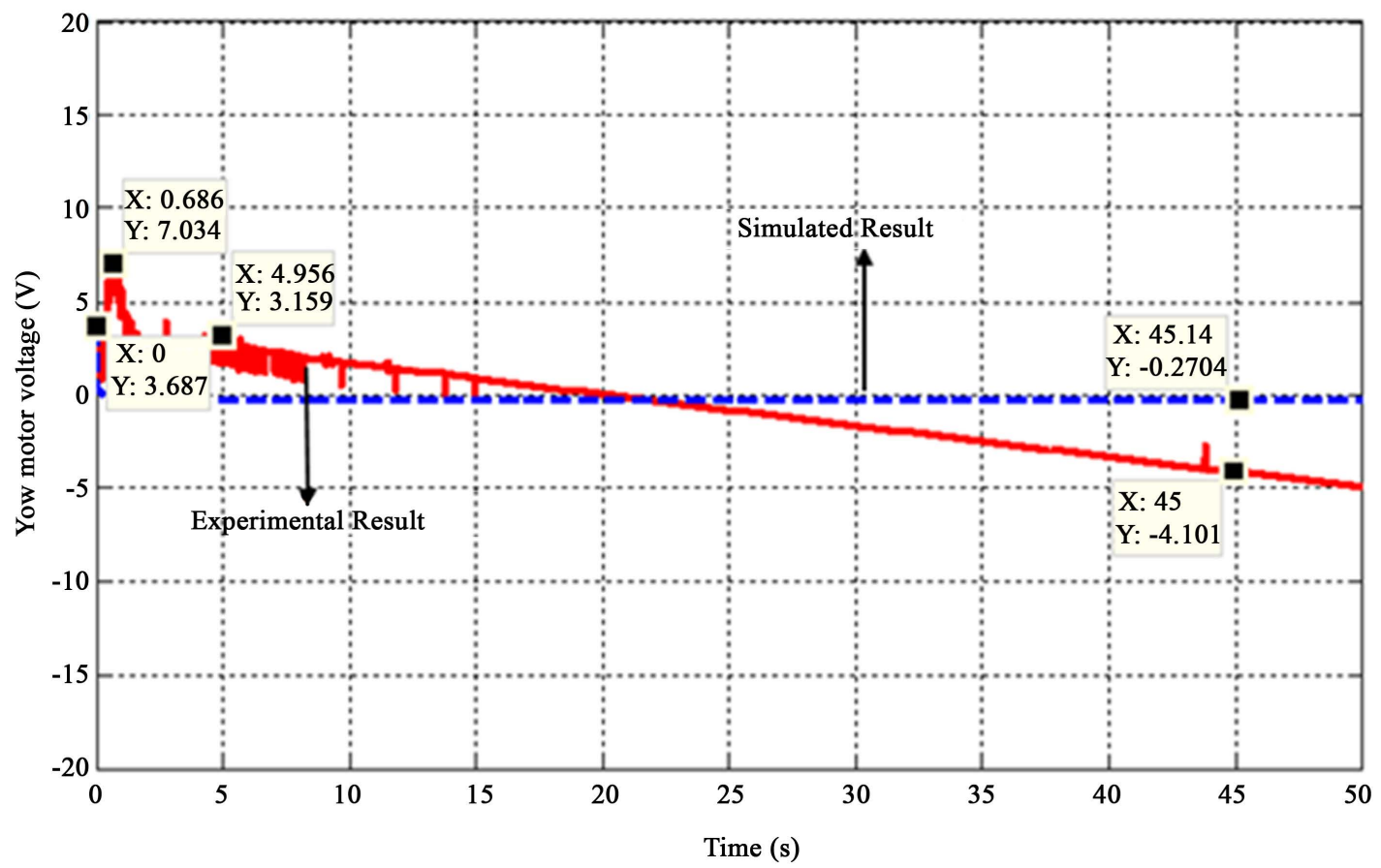

(c)

Figure 5. LCADRH MIMO system outputs (a) LQR controlled closed loop position response under yaw step input (b) and (c) Motor input voltages.

This shows the absence of coupling effect of yaw actuator on pitch axis in LQR closed loop position control of LCADRH.

\subsection{Case III-Pitch Square Input}

In case III, square input of 5 degree with a periodicity of 20 seconds is given as desired set point for pitch to analyze the forward and backward movement of LCADRH and its corresponding coupling impact on yaw. The simulated result of pitch angle and yaw angle follows the desired set point of pitch and yaw angle. As shown in Figure 6(a), experimental result illustrates that the rotation of LCADRH about yaw axis is by 5.537 degree at $\mathrm{t}$ $=20.62 \mathrm{~s}$ due to the rise of elevation about pitch axis. When the desired pitch angle is raised from -5 degree to 5 degree and decreased from 5 degree to -5 degree, measured yaw angle rotates clockwise and anticlockwise by 1 degree. This measure of side to side motion of LCADRH proves the inherent presence of coupling existence between pitch and yaw actuators. Initially, the negative potential voltage is applied to the yaw motor as shown in Figure 6(c).

\subsection{Case IV-Yaw Square Input}

In case IV, square input of 30 degree with a periodicity of 20 seconds is given as desired set point for yaw to analyze the side to side motions of LCADRH and its corresponding coupling impact on pitch actuator. Figure 7 shows that the simulated pitch and yaw response tracks desired pitch and yaw angle with less steady state error. For a given desired yaw angle, the body of LCADRH rotated clockwise and in an anticlockwise direction with less steady state error. The coupling impact of yaw actuator on pitch actuator is reduced by the LQR position controller.

\section{Conclusions}

The LCADRH is designed and developed for the academic research on control system experiments in educational institution. The real time measurement and control of helicopter is provided by integrating with data 

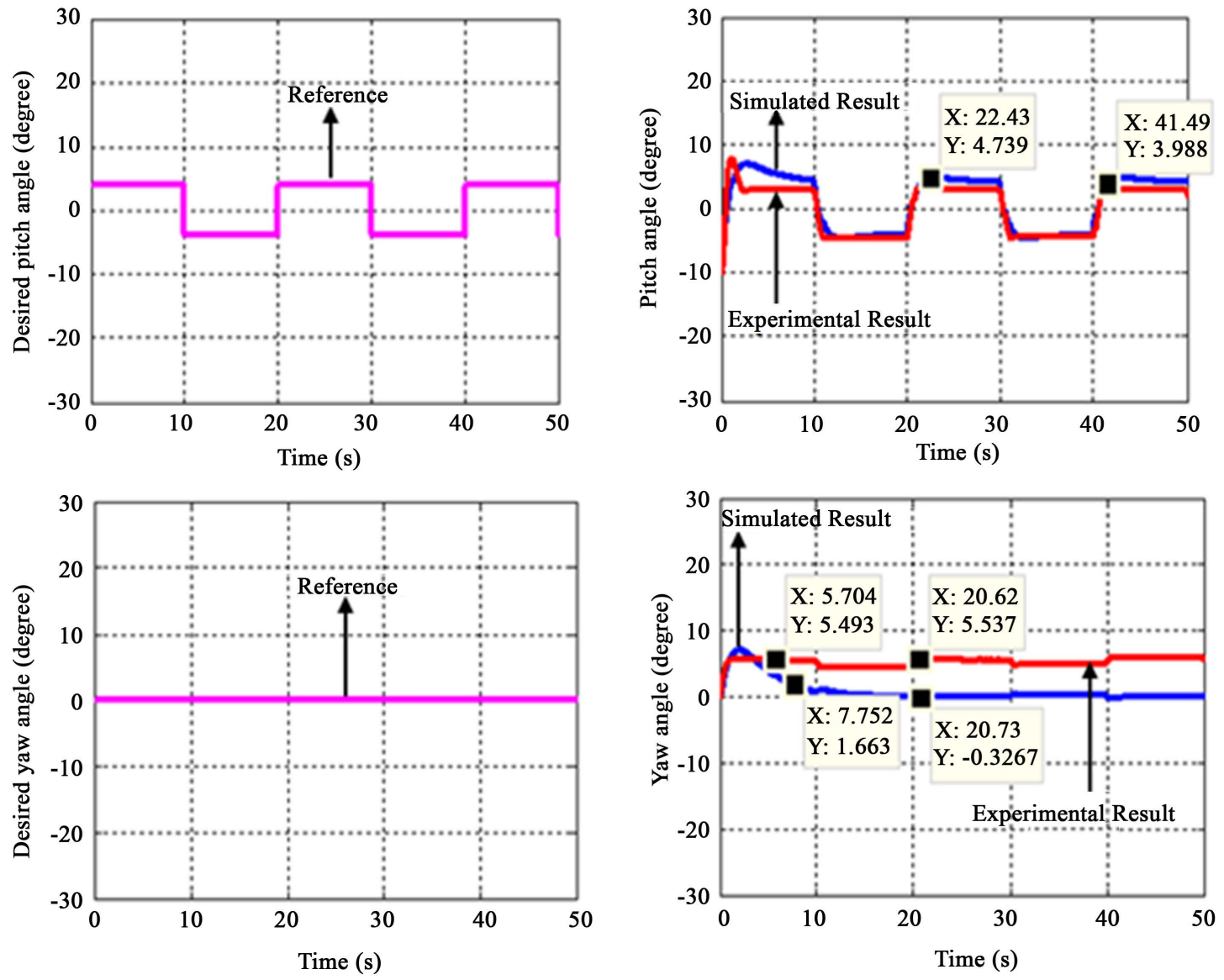

(a)

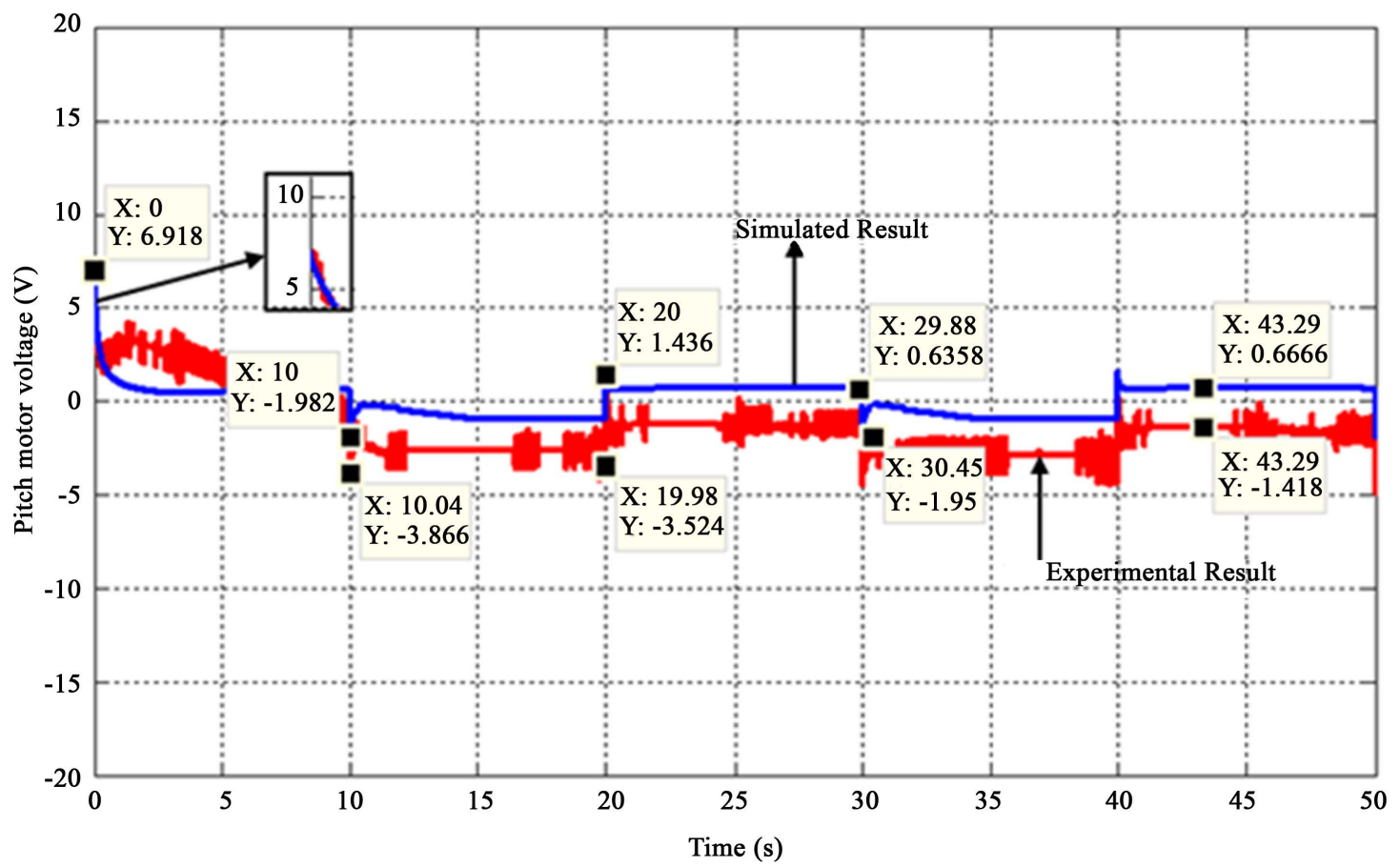

(b) 


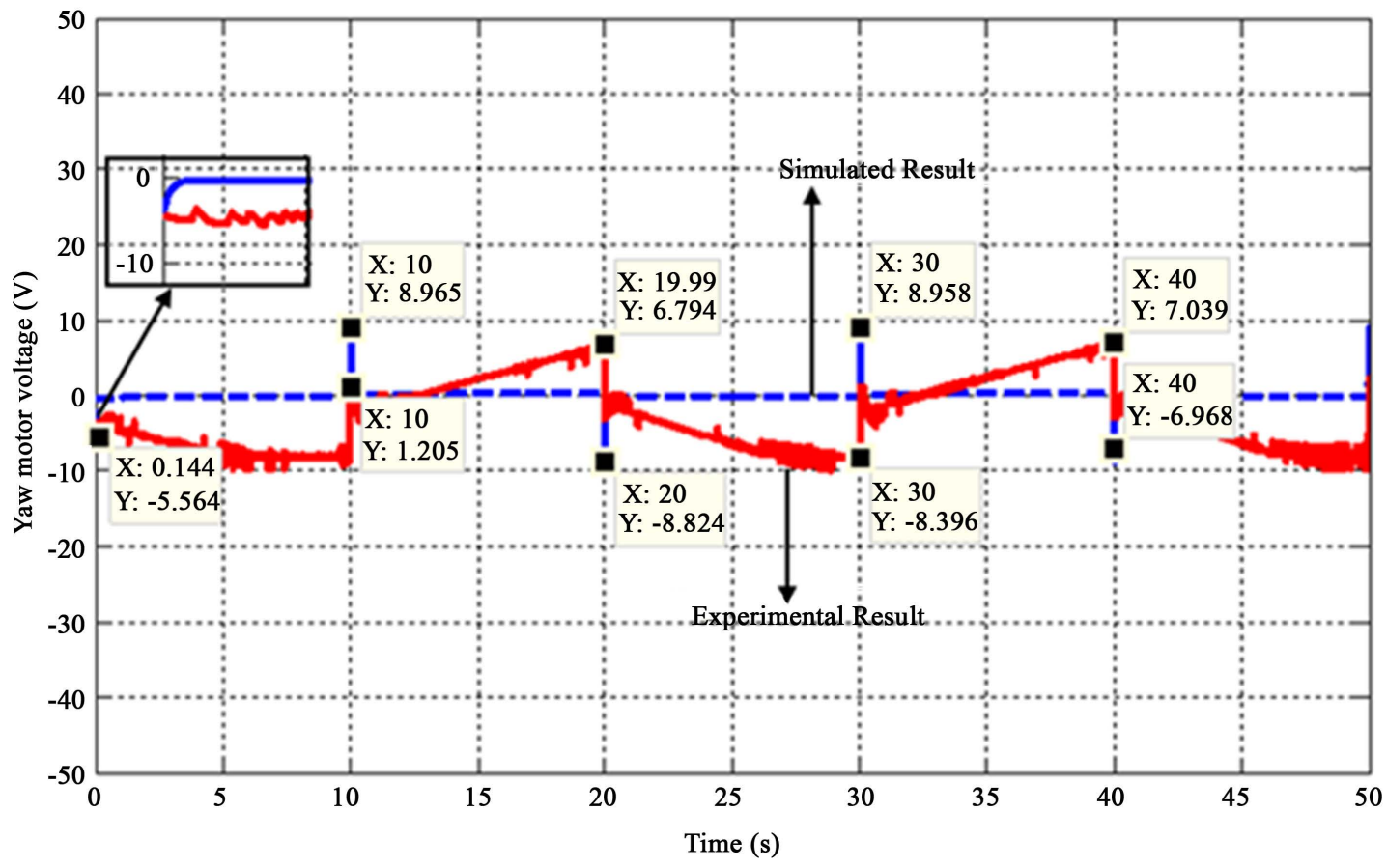

(c)

Figure 6. LCADRH MIMO system outputs (a) LQR controlled closed loop position response under pitch square input (b) and (c) Motor input voltages.
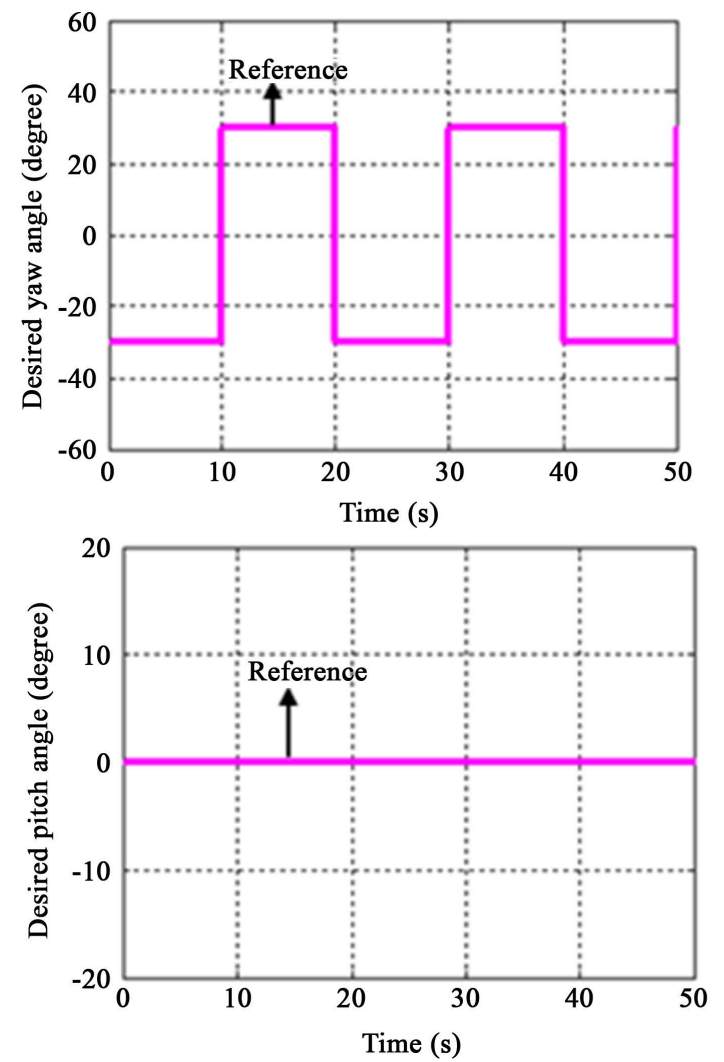
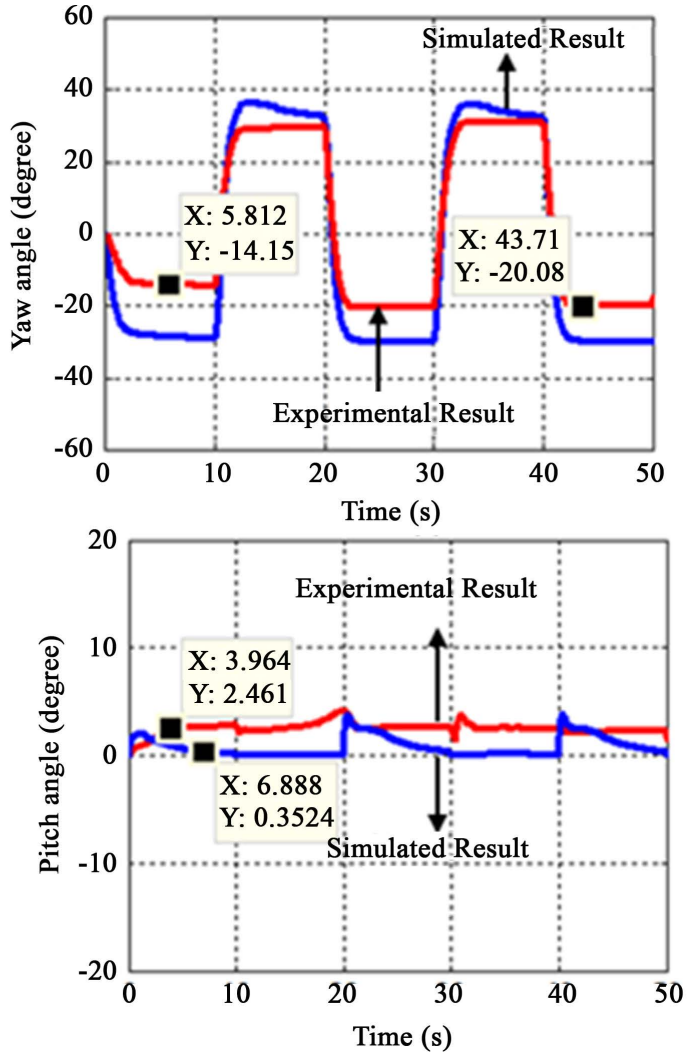

(a) 


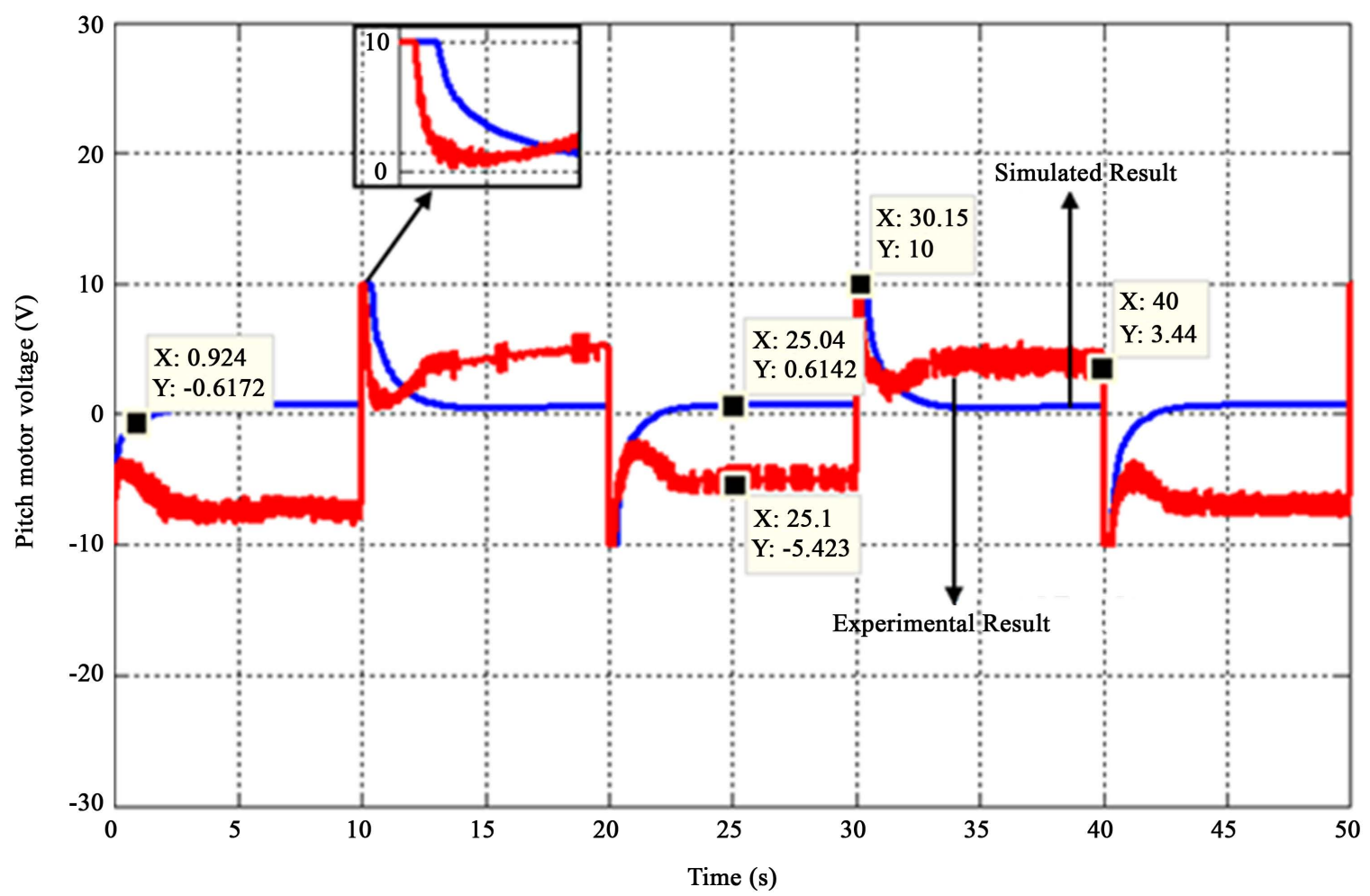

(b)

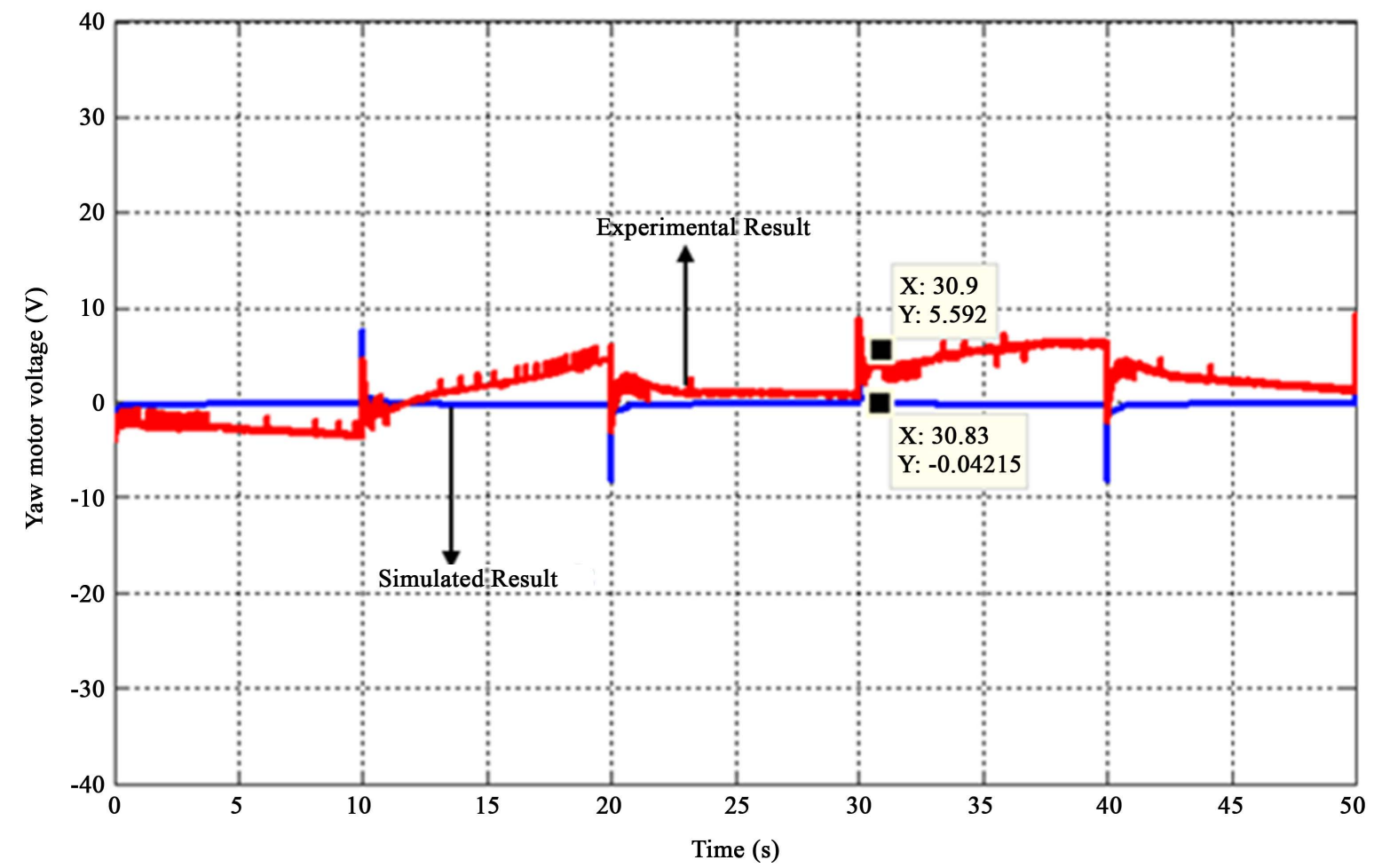

(c)

Figure 7. LCADRH MIMO system outputs (a) LQR controlled closed loop position response under yaw square input (b) and (c) Motor input voltages. 
acquisition board and sensors to provide hardware features, software support capability. The mathematical modelling of LCADRH is identified from its real input output data using grey box modelling. LQR controller is designed for LCADRH for the pitch and yaw position control. The coupling effect, nonlinearity and system dynamics of LCADRH is analyzed using experimental setup by giving step and square wave input. The simulation results of pitch and yaw angle follows the desired angle with less steady state error. The experimental results of pitch and yaw position shows the absence of structural vibration, oscillation and measurement noise. The designed LQR position controller controls elevation and side to side motion with consistent tracking of desired pitch and yaw angle and it reduces the existence of coupling effect between pitch actuator and yaw actuator.

Because of its cost effective nature, the proposed LCADRH model can be developed in third world countries giving the under graduate and post graduate students an affordable opportunity to learn modelling, simulation, and control oriented experiments in a non linear coupled MIMO system.

\section{Acknowledgements}

The authors gratefully acknowledge Dr. S. Baskar, Professor, EEE, Thiagarajar College of Engineering, Madurai, for his meticulous guidance, encouragement and his valuable discussions. One of the authors of this paper (P.S. Manoharan) acknowledges Science and Engineering Research Board, Department of Science and Technology (DST), India for sanctioning the funding under Fast Track Young Scientist Scheme, vide sanction number SERB/F/2056/11-12 dated 15.02.2012.

\section{References}

[1] Quanser Innovate Educate, Aerospace Plant: 2-DOF Helicopter Position Control Manual, Canada, 2006.

[2] TRMS 33-949S User Manual, Feedback Instruments Ltd., East Sussex.

[3] Ahmad, S.M., Chipperfield, A.J. and Tokhi, O. (2000) Dynamic Modeling and Optimal Control of a Twin Rotor MIMO System. IEEE Conference on National Aerospace and Electronics, 391-398. http://dx.doi.org/10.1109/naecon.2000.894937

[4] Subudhi, B. and Jena, D. (2009) Nonlinear System Identification of a Twin Rotor MIMO System. TENCON 20092009 IEEE Region 10 Conference, 1-6.

[5] Liu, H., Lu, G. and Zhong, Y.S. (2013) Robust LQR Attitude Control of a 3-DOF Laboratory Helicopter for Aggressive Maneuvers. IEEE Transactions on Industrial Electronics, 60, 4627-4636. http://dx.doi.org/10.1109/TIE.2012.2216233

[6] Dong, X.C., Zhao, X.X. and Shu, M. (2008) Research of Control Method Based on 3-DOF Twin Rotor MIMO System. Intelligent Control and Automation, 3279-3283.

[7] Wu, J., Peng, H., Chen, Q. and Peng, X.Y. (2014) Modeling and Control Approach to a Distinctive Quadrotor Helicopter. ISA Transactions, 53, 173-185. http://dx.doi.org/10.1016/j.isatra.2013.08.010

[8] Ljung, L. (1999) System Identification: Theory for the User. 2nd Edition, Prentice Hall PTR, Upper Saddle River. http://dx.doi.org/10.1002/047134608x.w1046

[9] Ljung, L. (2003) System Identification Toolbox User’s Guide. The Math Works, Inc.

[10] Grauer, J., Conroy, J., Hubbard, J., Humbert, J. and Pines, D. (2009) System Identification of a Miniature Helicopter. Journal of Aircraft, 46, 1260-1269. http://dx.doi.org/10.2514/1.40561

[11] Yuan, W. and Katupitiya, J. (2011) A Time-Domain Grey Box System Identification Procedure for Scale Model Helicopters. Proceedings of Australasian Conference on Robotics and Automation.

[12] Mettler, B., Tischler, M.B. and Kanade, T. (2002) System Identification Modeling of a Small Scale Unmanned Rotorcraft for Flight Control Design. Journal of the American Helicopter Society, 47, 50-63. http://dx.doi.org/10.4050/JAHS.47.50

[13] Zhao, Y., Huangb, B., Su, H.Y. and Chu, J. (2012) Prediction Error Method for Identification of LPV Models. Journal of Process Control, 22, 180-193. http://dx.doi.org/10.1016/j.jprocont.2011.09.004

[14] Brian, D.O., Anderson and Moore, J.B. (1989) Optimal Control: Linear Quadratic Methods. Prentice-Hall International, Inc., Englewood Cliffs.

[15] Vinodh Kumar, E. and Jerome, J. (2013) Robust LQR Controller Design for Stabilizing and Trajectory Tracking of Inverted Pendulum. Procedia Engineering, 64, 169-178. http://dx.doi.org/10.1016/j.proeng.2013.09.088

[16] Yu, G.-R. and Liu, H.-T. (2005) Sliding Mode Control of a Two-Degree-of-Freedom Helicopter via Linear Quadratic Regulator. Systems, Man and Cybernetics, 4, 3299-3304. http://dx.doi.org/10.1109/ICSMC.2005.1571655 
[17] Velagic, J. and Osmic, N. (2010) Identification and Control of 2DOF Nonlinear Helicopter Model Using Intelligent Methods. Systems Man and Cybernetics (SMC), 2267-2275.

[18] Kaloust, J., Ham, C. and Qu, Z. (1997) Nonlinear Autopilot Control Design for a 2-DOF Helicopter Model. IEE Proceedings of the Control Theory and Applications, 144, 612-616.

[19] Ramalakshmi, A.P.S. and Manoharan, P.S. (2012) Non-Linear Modeling and PID Control of Twin Rotor MIMO System. Proceedings of IEEE Conference on Advanced Communication Control and Computing Technologies, 366-369. http://dx.doi.org/10.1109/icaccct.2012.6320804

[20] Juang, J.-G., Liu, W.-K. and Lin, R.-W. (2011) A Hybrid Intelligent Controller for a Twin Rotor MIMO System and Its Hardware Implementation. ISA Transactions, 50, 609-619. http://dx.doi.org/10.1016/j.isatra.2011.06.006

\section{Submit or recommend next manuscript to SCIRP and we will provide best service for you:}

Accepting pre-submission inquiries through Email, Facebook, LinkedIn, Twitter, etc.

A wide selection of journals (inclusive of 9 subjects, more than 200 journals)

Providing 24-hour high-quality service

User-friendly online submission system

Fair and swift peer-review system

Efficient typesetting and proofreading procedure

Display of the result of downloads and visits, as well as the number of cited articles

Maximum dissemination of your research work

Submit your manuscript at: http://papersubmission.scirp.org/ 